Journal of Contemporary Research in Business, Economics and Finance

ISSN: 2641-0265

Vol. 2, No. 1, pp. 1-17

2020

Publisher: Learning Gate

DOI: 10.33094/26410265.2020.21.1.17

(C) 2020 by the authors; licensee Learning Gate

\title{
A Systematic Review of Factors Influencing Supply Chain Performance Outcomes
}

\author{
G. Tony Bell \\ Rutgers University, USA. \\ Email: gbell@rutgers.edu \\ John Sherlock \\ Western Carolina University, USA. \\ Email: Sherlock@wcu.edu
}

Received: 3 January 2020; Revised: 24 January 2020; Accepted: 12 February 2020; Published: 27 February 2020

\begin{abstract}
The concept of supply chain management (SCM) is receiving greater attention among academics and organizations and is viewed as a potential source of bottom and top-line growth. Despite the potential for improving organizational performance through supply chain improvements, little scholarly evidence exists in management literature to establish an association between organizational factors and SCM performance outcomes. This paper focuses on an understanding of those factors by providing a systematic review of 21 empirical studies, whereby an evidence-based analysis of the findings from this research indicates that four organizational factors (people orientation, process orientation, information technology, and external environment) are associated with SCM performance outcomes. Although the paper initially sought to identify specific factors associated with successful supply chain outcomes, the evidence led to the importance of a fifth factor, supply chain integration, and its impact on supply chain performance. Moreover, the paper discusses the managerial implications of supply chain integration and identifies the need for improved competency among supply chain managers to further bring supply chain integration to life.
\end{abstract}

Keywords: Supply chain, Supply chain management, Logistics management, Performance, Outcomes, Effectiveness.

\section{Introduction}

Supply chain management (SCM) is considered a new world order of relationships among various functions, such as planning, procurement, manufacturing and logistics; and, it has become an increasingly important topic within the field of management due to growing marketplace complexity and the desire for organizations to gain a competitive advantage (Fabbe-Costes \& Jahre, 2008). SCM is defined as the management of a network of multiple entities (organizations or individuals), which are directly involved in the flow of products, services, and information from source to consumer - for the purpose of creating value for the end consumer (Mentzer et al., 2001; Stock \& Boyer, 2009). The value of effective SCM to participating organizations is evident in how companies like Zara, Wal-Mart, and Proctor \& Gamble have leveraged their supply chains to gain a competitive advantage (Hult, Ketchen, \& Arrfelt, 2007). However, according to Deshpande (2012) management practitioners and academicians have been relatively unsuccessful in the effective implementation of SCM principles. Chen and Paulraj (2004a) assert that one reason for SCM implementation failures is disagreement among researchers regarding the critical dimensions of SCM in addition to challenges surrounding the development of the 
appropriate SCM performance measures (Beamon, 1999). Regardless, SCM appears to bear significant costs to our national economy.

In 2017 U.S. business logistics expenditures (primarily transportation and warehousing functions) accounted for an estimated $\$ 1.5$ trillion or $7.7 \%$ of U.S. GDP, representing a $6.2 \%$ increase over 2016 (Kearney, 2017). Figure 1 illustrates this recent rise in U.S. logistics costs (as a percentage of GDP) after a modest decline in 2016. In all, this data reflects a rising trend in U.S. logistics costs and implies the desire for organizations to focus on leveraging their supply chains to reduce costs and improve the profit outlook for the organization.

\section{Business logistics costs have increased to $7.7 \%$ of GDP $\%$ of nominal GDP}

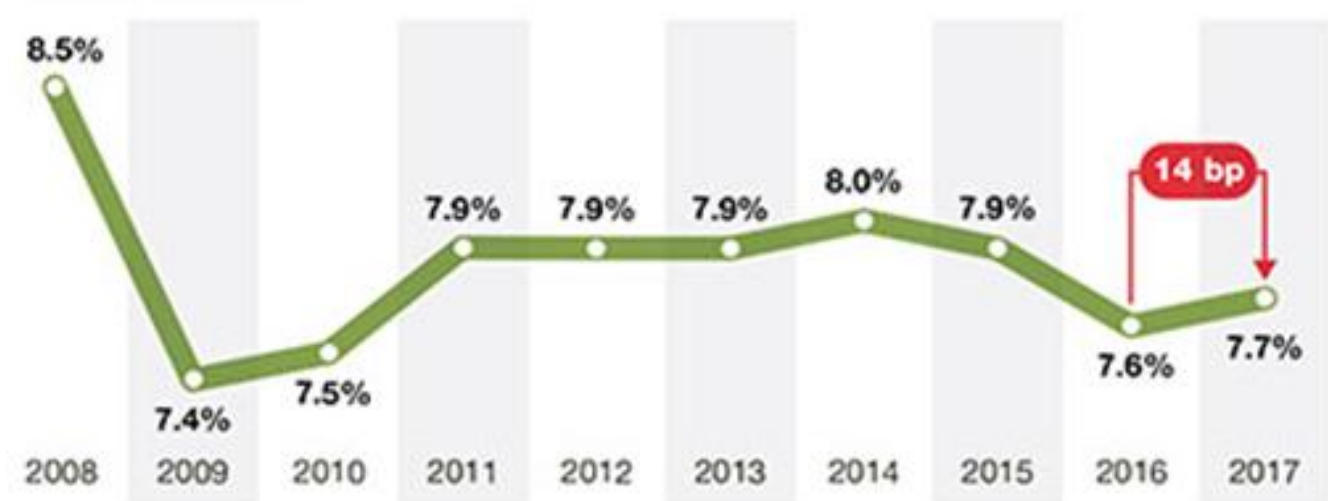

Figure-1. U.S. logistics costs as a percentage of U.S. GDP, 2008 to 2017. Adapted from "29 State of Logistics Report” by A.T. Kearney, Council of Supply Chain Management Professionals (CSCMP), and Penske Logistics, 2017.

Note: bp is basis points.

This research seeks to fill an existing knowledge gap relative to identifying the organizational factors associated with SCM performance outcomes by posing the following question: Which organizational factors are associated with SCM performance outcomes? Also, the research seeks to determine the impact of these factors on SCM performance outcomes as well as the level of interdependence among them because such determination allows management scholars and practitioners to make more informed decisions regarding future supply chain research and practice.

The research is intended to provide greater direction and insight for leaders within organizations to identify the key factors drawn from various pieces of literature and empirical studies. In addition, this guidance can be leveraged to develop a deeper understanding and meaning to SCM performance and, potentially, a more comprehensive framework for supply chain performance measurement. According to Brewer and Speh (2000) those managers who are well educated in the field of SCM are struggling with the concept of supply chain performance due to the lack of a widely-accepted SCM performance framework.

\section{Research Methods}

The guidelines for conducting a systematic review of the literature were based on the evidencebased research methodology of Petticrew and Roberts (2006) and the perspectives of Rousseau, Manning, and Denyer (2008) and Reay, Berta, and Kohn (2009). The research also leveraged an adaptation of Thomas and Harden (2008) thematic synthesis methodology, which is an evidence-based research synthesis (EBRS) approach designed to analyze, integrate, and configure qualitative or mixedmethod research. For simplicity purposes, the systematic logic of Gough (2007) was used to outline the 
eight research steps as illustrated in Figure 2. Evidence-based research has its roots in the evidence movement, which includes such concepts as evidence-based medicine, evidence-based public policy, and evidence-based management (Briner, Denyer, \& Rousseau, 2009). In the last two decades, evidencebased research has been widely accepted and practiced across several fields, such as education, medicine, and psychology (Rousseau \& McCarthy, 2007). Therefore, it appears that evidence-based research is quite applicable to a variety of fields, including the field of management.

This research approach involves a systematic process for identifying the best available scientific evidence, whereby the identified evidence influences management decisions and organizational practices (Rousseau \& McCarthy, 2007). Also, this approach is essential to the process of identifying and evaluating quality evidence most relevant to theory development and practical application.

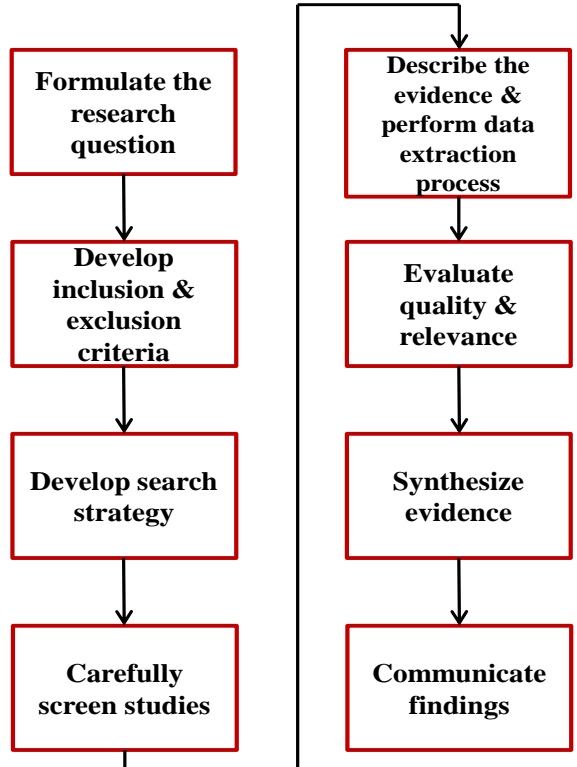

Figure-2. Evidence-based research steps. Adapted from "Weight of Evidence: A Framework for the Appraisal of the Quality and Relevance of Evidence," by Gough (2007) Research Papers in Education, 22(2), p. 218.

Source: Stages of a review.

\subsection{Search Strategy}

An exhaustive search of the literature began with the development of a list of keywords associated with supply chain management and successful outcomes - i.e. performance factors. Development of the keyword list strongly considered the definition of supply chain as provided by Mentzer et al. (2001) and APICS-The Association for Operations Management (2008). The search process was primarily focused on scholarly literature specific to the constructs of supply chain, logistics, performance, and effectiveness in an effort to specify "successful outcomes." The search process was further refined and resulted in generation of the following queries: supply chain AND performance; supply chain management AND performance; supply chain AND effectiveness; supply chain management AND effectiveness; supply chain AND success factors; logistics AND performance; logistics AND effectiveness; operations management AND performance; operations management AND effectiveness; and physical distribution AND performance. These keyword combinations were used to access several business, management, and social sciences databases via University of Maryland University College's (UMUC) Information and Library Services. Specifically, a search of the following electronic databases was performed: Business Source Complete, Emerald Fulltext and Management Reviews, Web of Science (Social Sciences Citation 
Index), Science Direct, ABI/INFORM Complete, and JSTOR. Google searches and searches within the Academy of Management (AMA) and the Council of Supply Chain Management Professionals (CSCMP) websites were performed to identify dissertations and theses on the subject of SCM and performance factors. Also, the World Wide Web was accessed to identify pertinent SCM statistics, additional articles and scholarly books. In addition, studies were identified by scrutinizing the reference lists of the obtained publications.

\subsection{Evaluation of Research Studies}

The initial search resulted in the generation of 139 scholarly works, including empirical studies, opinion pieces, dissertations, theses and books in the field of SCM. The article abstracts were reviewed in detail and the remainder of the article content was skimmed to ensure the article addressed the nature of the study. Articles were excluded for the following reasons: 1) article did not address some level of relationship between SCM performance outcomes and associated organizational factors; 2) article focused on only one functional area of the supply chain (such as manufacturing or transportation). Figure 3 below illustrates the process employed to determine the final dataset for the SR analysis. As indicated, 91 items were rejected based on a review of the article's title and abstract, which lacked relevance to the research question. Forty-eight items were retained for further review. Another 27 items were excluded at the synthesis stage because they failed to meet the minimum quality threshold.

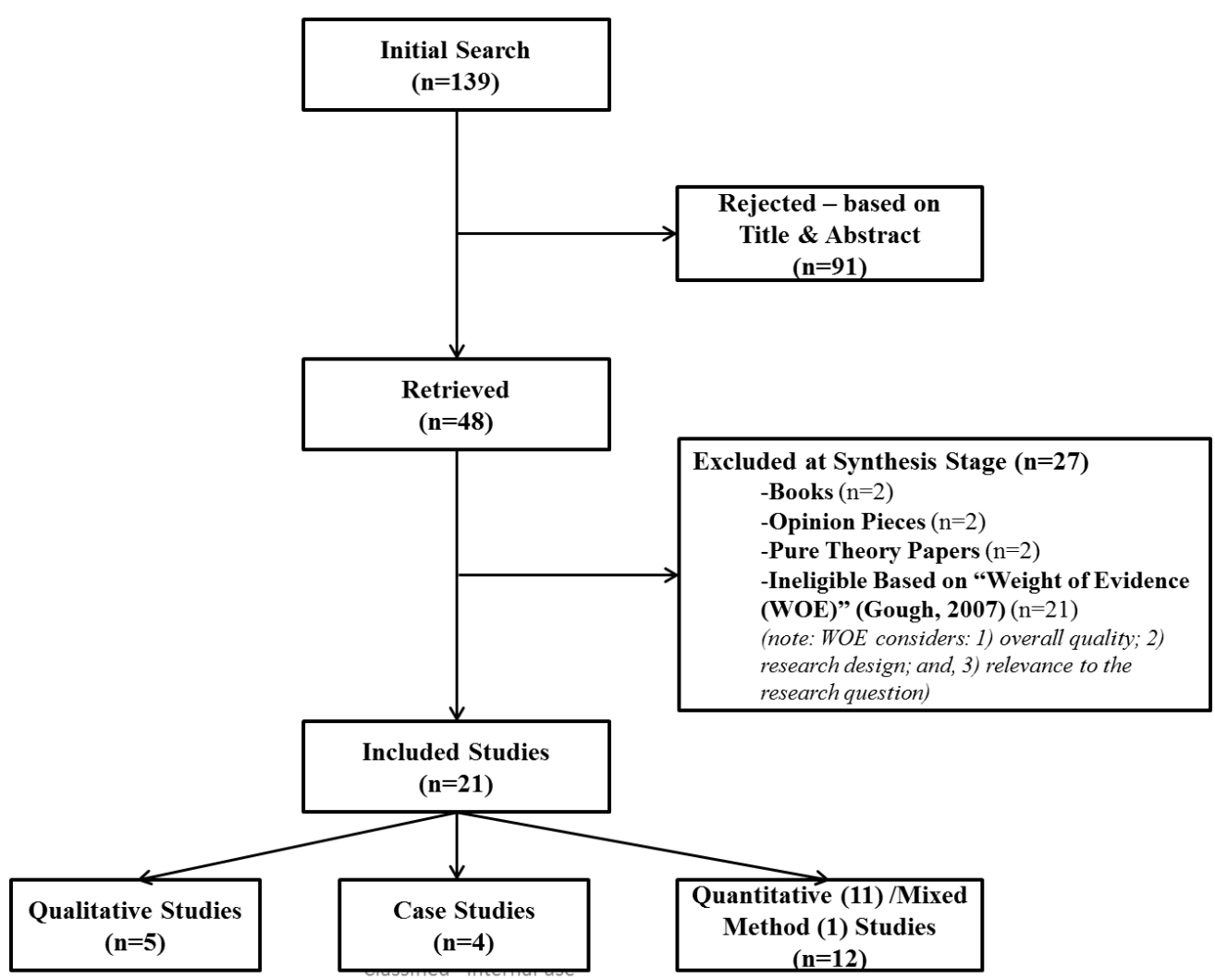

Figure-3. Search process flow chart.

The information collected on each study provides the author the ability to judge the usefulness of the findings for responding to the research question (Gough, 2007). Once the evidence has been identified, the synthesis of this evidence (i.e., evidence-based research synthesis, or EBRS) follows. EBRS involves the collection, analysis, and interpretation of a body of research studies in response to a 
particular research question (Rousseau et al., 2008). EBRS also allows the researcher to direct future research, identify research gaps, and share findings with practitioners in the field (Rousseau et al., 2008). Moreover, the scope of EBRS includes the application of a systematic process for assembling, categorizing, and analyzing a comprehensive body of literature based on certain criteria (Rousseau et al., 2008). Figure 3 illustrates the detailed flow associated with the search process.

The research studies were assessed based on a "Weight of Evidence" (WoE) framework proposed by Gough (2007) in accordance with its 3-level rating dimensions (WoE - A, B, C) as illustrated in Figure 4. The rating dimensions are used by the researcher to produce an overall judgment on the article (WoE - D).

\section{Weight of Evidence}

Category A - Overall Quality

- $\quad$ Purpose of the research - the research purpose is explicit and clear

- Completeness of study - the study clearly includes key aspects of a research study (e.g. research question, hypothesis, literature review, method, findings, implications)

- Category B - Research Design

- Constructs - themes or constructs are clearly developed

- $\quad$ Method - the research methodology employed in the study is appropriate for the research question

- Category $\mathrm{C}$ - Relevance (to the research question)

- $\quad$ Research question alignment - the study provides conclusions that are relevant to addressing the research question

- Implications for future management research \& practice - the study provides direction for management researchers and practitioners

Figure-4. Weight of evidence dimensions. Adapted from "Weight of Evidence: A Framework for the Appraisal of the Quality and Relevance of Evidence," by Gough (2007) Research Papers in Education, 22(2), p. 224.

\section{Findings}

Figure 5 represents a synthesis map displaying an overview of the associations uncovered in the evidence. These associations can be characterized by a link between several keywords extracted from the studies and SCM performance factor groupings developed from the comprehensive list of extracts, followed by a link to the major factors identified in the literature review. In most cases, the extracts are mentioned within the context of their association with supply chain performance.

An examination of the literature revealed four primary factors which characterized the major organizational factors associated with SCM performance outcomes: (a) people orientation; (b) process orientation; (c) information technology; and, (d) external environment are discussed within the context of the literature reviewed.

\subsection{People Orientation}

Findings from the evidence suggest that people orientation is a primary factor associated with SCM performance outcomes. Seventeen of the 21 studies in the dataset contained some reference, either in the Findings or Conclusion section (or both), to sub-factors attributed to the people orientation. Text excerpts were pulled from various sections within the studies and coded into the most relevant subfactor grouping. Per Figure 5, increased communication was coded to the sub-factor, generically labeled communication; inter-team collaboration was coded to the sub-factor, willingness to collaborate; and, support from middle and senior managers was coded to the sub-factor, top management support. The logic behind this coding is based on the human elements involved in the supply chain manager's ability to communicate, willingness to engage with teams, and ability to secure top management support for relevant supply chain projects and initiatives. Intuitively, these interpersonal skills were, subsequently, coded to the major factor, people orientation. A similar approach was used for the remaining organizational factors. 


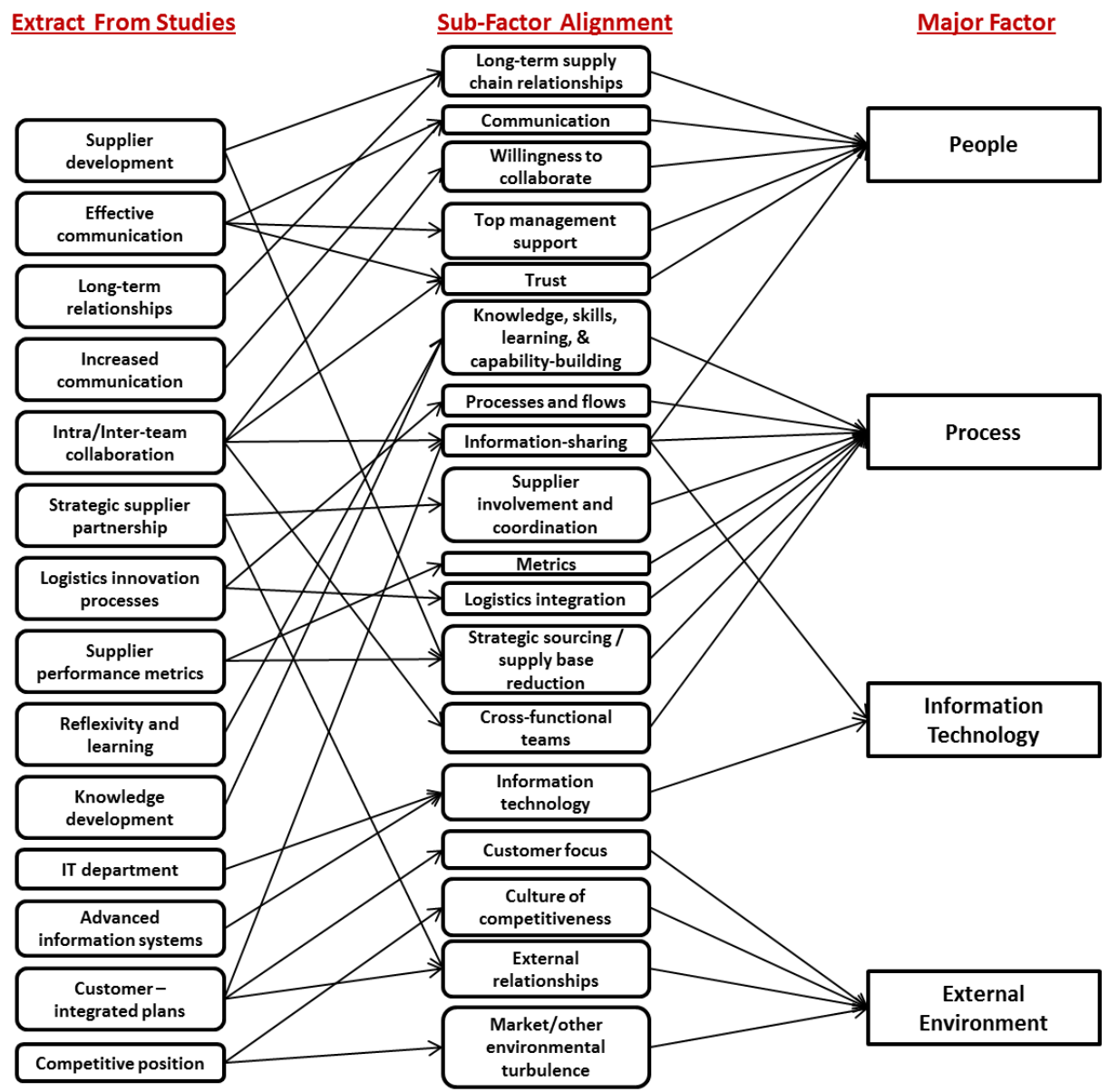

Figure-5. Data analysis \& synthesis process.

In their research on supply chain bridges, barriers, and benefits, Fawcett, Magnan, and McCarter (2008) proposed that human resource issues, such as lack of trust, power plays, and overall unwillingness to change or collaborate with trade partners are clear barriers to building effective strategic supply chains. The authors imply that such barriers can be removed through more structured (e.g. top-to-top meetings) and consistent (e.g. quarterly) collaboration between trade partners, which may also include sharing of data and best practices. Even Zacharia, Nix, and Lusch (2009) viewed supply chain collaboration and its benefits from this "operational" and "relational" perspective. According to Zacharia et al. (2009) a high level of supply chain collaboration exists when trade partners define joint goals and objectives, freely share information (e.g. sales data), and share process knowledge and skills. This open willingness to work more closely toward a win-win scenario for the partner firms can potentially result in an increase in trust and decrease in power struggle between the organizations. More importantly, Zacharia et al. (2009) suggested that operational metrics, such as on-time delivery and invoice accuracy, must be positive before collaboration can occur.

\subsection{Process Orientation}

Another organizational factor associated with SCM performance outcomes is process orientation, whereby 20 of the 21 studies in the dataset referred to the important role process plays in supply chains. Themes, such as supplier selection; customer-integrated plans and schedules; and, metrics were coded to process orientation because the outcomes associated with these themes require detailed process development. For example, the metrics sub-factor was coded to process orientation because the development of a 
performance measurement system is highly dependent on the organization's ability to develop processes to ensure consistent and sustained measurement practices. Ramdas and Spekman (2000) conclude that high-performing organizations adopt processes and systems designed to measure supplier performance, carrier performance, and customer satisfaction. Moreover, the adoption of a performance measurement system by high-performing organizations often results in improved SCM performance outcomes (Ramdas \& Spekman, 2000). The use of such metrics to measure and monitor supply chain partner performance and customer satisfaction is highly aligned to the sub-factor, metrics; and, ultimately, process orientation because the development of a performance measurement system is highly dependent on the organization's ability to develop processes to ensure consistent and sustained measurement practices. In addition, high-performing organizations develop detailed plans and schedules, which are highlyintegrated with their customer base, to support the organization's demand and supply planning process (Ramdas \& Spekman, 2000).

As early as the 1950's there was a clear focus on the basic premise of SCM and the importance of effective SCM-related processes. For example, in his work on industrial organization dynamics, Forrester (1958) examined approximately 40 business relationships, which were used to conduct simulation modeling of various business functions, such as production management, inventory control, and advertising. Forrester (1958) focus was on the operational processes associated with product and information flow and ignored "considerations of money, manpower, and capital equipment" (p. 41) as a means of improving supply chain effectiveness. According to Krabbe (2007) supply chain effectiveness occurs when organizations implement best practices by benchmarking existing processes and identifying short and long-term objectives (through development, measurement, and monitoring of key supply chain performance metrics) to ensure future efficiency gains and improved service (p. 26).

An interesting example from outside of the typical SCM industries also highlights the impact of integration. Webb (2017) discusses how WestJet Airlines seeks to optimize its technology investments through stronger process integration- to further improve customer satisfaction. "The most successful airline operations leverage unified technology in a way that sets the stage for better-integrated business processes all around the company, linking different departments with real-time data to shape decisionmaking" (Webb, 2017). Webb (2017) goes on to mention that, while airline companies have invested wisely in technology applications to support their business operations, much more can be done to improve the integration of the various processes across multiple departments that are enabled by these systems.

\subsection{Information Technology}

Information technology was identified as another factor associated with SCM performance outcome because, in 17 of the 21 studies, the term information technology or information-sharing was explicitly mentioned. Themes related to technological enablers, such as system hardware, software, and data integration or sharing were all aligned with the information technology factor. For example, Crook, Giunipero, Reus, Handfield, and Williams (2008) and Fawcett et al. (2008) refer to the organization's use of relevant SCM technology applications as an enabler for SCM effectiveness. In their work on supply chain information technology, Vickery, Droge, Setia, and Sambamurthy (2010) examined the impact of information technology and organizational initiatives on agility and performance in manufacturing firms. Examples of organizational initiatives as it pertains to information technology include implementation of: automated manufacturing systems, warehouse management systems (WMS), and integrated electronic data interchange (EDI). The authors posited that supply chain information technology and organizational initiatives have separate and complementary effects on agility and performance within these organizations. However, the use of information technology, as a supply chain "process" enabler, often requires an abundance of data, some of which relies on information (e.g. inventory position, point-of-sale data) obtained from trade partners to improve system accuracy. In

fact, Narasimhan, Kim, and Tan (2008) described the information sharing strategy typology as the use of electronic exchange of information among SCM partners to improve SCM performance. For example, 
information sharing between suppliers and their customers can assist suppliers in obtaining greater demand predictability. In addition, information sharing can be used to identify distribution network improvement opportunities. The authors found that a vital input to the development of an effective SCM strategy is the pursuit of advanced information systems and technologies designed to improve the level of communication between suppliers, customers, and their SCM partners (Narasimhan et al., 2008).

\subsection{External Environment}

The external environment plays an important factor in the organization's SCM performance outcomes, whereby 10 of the 21 studies in the dataset were found to have contained specific references to sub-factors attributed to the external environment. The factor, external environment, is designed to capture those activities -such as those related to the customer, the economy, and competition- associated with SCM performance outcomes, yet are external to the organization. For example, one of the primary objectives of the Tan, Kannan, Handfield, and Ghosh (1999) study is to determine the overall impact of an organization's competitive position on SCM performance. Text excerpts from the study include competitive environment and competitive position. Both excerpts were coded to the sub-factor, culture of competitiveness, which links to the major factor, external environment. The underlying logic behind this coding is that an organization's competitive position is based on how it compares to rival organizations, which are external to the impacted organization.

Ramdas and Spekman (2000) attempted to better understand the dominant factors of SCM performance by highlighting the shift in the external market trends toward greater product variety and customization undertaken by high performing organizations. It is implied that this shift toward directed consumer segmentation provides organizations with the demand for an effective and competitive supply chain strategy. Hult, Ketchen, and Arrfelt (2007) leveraged the resource-based view (RBV) of the firm by linking the organization's knowledge management and development practices with supply chain effectiveness and performance as it relates to the organization's ability to maintain or reduce cycle-time during difficult market conditions. Hult, Ketchen, and Chabowski (2007) argued that a culture of competitiveness and knowledge development, as separate variables, will not necessarily result in improved supply chain performance. However, adopting a combined culture of knowledge development and competitiveness, while keeping abreast of changing market conditions, can ultimately lead to improved cycle-time performance.

\subsection{The Fifth Factor: Supply Chain Integration}

Although the initial purpose of the research was to identify and analyze the organizational factors associated with SCM performance outcomes, the body of evidence revealed an enlightening and refreshing discovery of a fifth organizational factor: supply chain integration. The evidence found that the key to successful SCM outcomes is the use of these organizational factors as primary "inputs" for the supply chain integration of external trading partners (e.g. supplier-to-customer) and the subsequent integration of internal functions (e.g. plan, deliver) to support external integration. Furthermore, the factors, themselves, must be fully integrated, working together in tangent, to achieve the greatest SCM performance outcomes.

\subsection{Defining the Fifth Factor}

Supply chain integration involves the development and execution of an integrative, or systems, approach to SCM with the goal of influencing SCM performance outcomes. Li (2007) defines supply chain integration as "the extent to which all activities within an organization, and the activities of its suppliers, customers, and other supply chain members, are integrated together" (p. 64). Also, Vickery, Jayaram, Droge, and Calantone (2003) describe the integrated supply chain as an integration of business processes, as opposed to individual resources, functions, and systems, designed the create value to the organization by incorporating the organization's customers and suppliers into the value-creation process. 
Table 1 reveals how the concept supply chain integration was evident in more than $85 \%$ of the body of evidence (i.e. articles) and was explicitly discussed and defined in more than $35 \%$ of the articles. For example, Li, Ragu-Nathan, Ragu-Nathan, and Rao (2006) discuss how information-sharing across functions and organizations leads to supply chain integration; and, more importantly, promotes reliable delivery and speed-to-market relative to new product introductions, which leads to improved performance. While 13 of the studies did not explicitly examine SCM integration, its importance could readily be inferred from the study's findings and discussion. For example, Deshpande (2012) describes the importance of integrating the customer into the manufacturer's supply chain for the purpose of minimizing inventory carrying costs for both parties.

Table-1.

Supply chain integration references.

\begin{tabular}{|c|c|c|c|c|}
\hline & "Inte & egration" & " Referen & ice \\
\hline $\begin{array}{l}\text { Article } \\
(\mathrm{n}=21)\end{array}$ & Explicit & Inferred & Defined & None \\
\hline $\begin{array}{l}\text { Brammer, Hoejmose, and Millington (2011) - } \\
\text { Managing sustainable global supply chains: A systematic review of the } \\
\text { body of knowledge }\end{array}$ & & $\mathrm{X}$ & & \\
\hline $\begin{array}{l}\text { Chen, Paulraj, and Lado (2004) - Strategic purchasing, supply } \\
\text { management, and firm performance }\end{array}$ & & $\mathrm{X}$ & & \\
\hline $\begin{array}{l}\text { Chen and Paulraj (2004a) - Towards a theory of supply chain } \\
\text { management: the constructs and measurements }\end{array}$ & & $\mathrm{X}$ & & \\
\hline $\begin{array}{l}\text { Chen and Paulraj (2004b) - Understanding supply chain management: } \\
\text { critical research and a theoretical framework }\end{array}$ & & $\mathrm{X}$ & & \\
\hline Crook et al. (2008) & & $\mathrm{X}$ & & \\
\hline Deshpande (2012) & & $\mathrm{X}$ & & \\
\hline Fabbe-Costes. and Jahre (2008) & $\mathrm{X}$ & & $\mathrm{X}$ & \\
\hline Fawcett et al. (2008) & $\mathrm{X}$ & & & \\
\hline Hellström and Nilsson (2011) & & $\mathrm{X}$ & & \\
\hline Hendricks and Singhal (2005) & $\mathrm{X}$ & & & \\
\hline Hult, Ketchen, and Arrfelt (2007) & & & & $\mathrm{X}$ \\
\hline Kamaladevi (2010) & & & & $\mathrm{X}$ \\
\hline Krabbe (2007) & & & & $\mathrm{X}$ \\
\hline Li. et al. (2006) & $\mathrm{X}$ & & & \\
\hline $\operatorname{Li}(2007)$ & $\mathrm{X}$ & & $\mathrm{X}$ & \\
\hline Narasimhan et al. (2008) & $\mathrm{X}$ & & $\mathrm{X}$ & \\
\hline Ramdas and Spekman (2000) & $\mathrm{X}$ & & & \\
\hline Su, Gammelgaard, and Yang (2011) & & $\mathrm{X}$ & & \\
\hline Tan et al. (1999) & & $\mathrm{X}$ & & \\
\hline Vickery et al. (2010) & $\mathrm{X}$ & & & \\
\hline Zacharia et al. (2009) & & $\mathrm{X}$ & & \\
\hline Total Count: & 8 & 10 & 3 & 3 \\
\hline
\end{tabular}

\subsection{Identifying the Fifth Factor}

Leveraging the example from Li et al. (2006) in the previous section, you can see that the sub-factor, "Information-sharing" was identified based on extracts from the studies that included concepts related to "intra/inter-team collaboration" and "customer-integrated plans" as both concepts rely heavily on the exchange of data, processes, and other relevant information between functions and across organizations 
(e.g. suppliers, customers). Therefore, there is a reasonable connection to the major factors, "people," "process," and "technology." However, one should not assume that no additional associations exist between the concepts found in the research extracts and the sub-factors as the associations in scope for this study are solely based on the 21 research studies in the dataset and identified for synthesis.

\subsection{Integration in-Motion}

In the spirit of best practice research, many examples of supply chain integration were identified through the data synthesis process. For example, several studies refer to supplier development and the importance of long-term relationships, which both link to the broader sub-factor, long-term supply chain relationships and, in turn, links to the people orientation factor. However, the reference to supplier development within selected studies also align with supplier involvement and collaboration, which links to the process orientation factor. In most cases, the extracts are mentioned within the context of their association with supply chain performance. Sticking with this example, supplier selection is a key step within the Strategic Sourcing and Procurement processes; and, the step able to provide significant cost savings to the organization in terms of the reduction of its supplier base (Chen \& Paulraj, 2004b). However, this step requires the use or development of detailed project plans, processes, and guiderails to adequately meet the organization's objective to select the appropriate suppliers based on well-develop criteria, such as cost, flexibility, and strategic importance. This implies not only the importance of integration among the identified factors (i.e. process, people), but the need for all factors to work in concert to ensure the appropriate decisions are made to positively impact total supply cost, a key component of supply chain performance and associated financial impact.

Crook et al. (2008) found that specialized SCM knowledge, complemented by information technology and trusted partnerships, is an important element for obtaining higher profits from the supply chain for all SCM partnering organizations. Specifically, "organizations must be willing to make investments in training and development geared towards creating a more diverse and knowledgeable workforce" (Crook et al., 2008). Although people orientation is an important factor influencing SCM performance, other factors, such as process, technology, and the external environment, are equally important to the maintenance and improvement of the organization's supply chain performance. For example, Ramdas and Spekman (2000) conclude that high-performing organizations adopt processes and systems designed to measure supplier performance, carrier performance, and customer satisfaction. In addition, high-performing organizations develop detailed plans and schedules, which are highly-integrated with their customer base, to support the organization's demand and supply planning process (Ramdas \& Spekman, 2000). Therefore, the development of customer-integrated supply and demand volume plans and schedules -intended to meet customer expectations- require that the appropriate processes and systems are in place to create those plans in collaboration with the customer. Furthermore, these demand plans and schedules must be fully aligned with current market conditions, such as the proactive development of plans that meet potential shifts in customer preferences (e.g. organic, natural products). In fact, Ramdas and Spekman (2000) found that innovative and high- performing organizations actively engage in activities aimed at gaining a strategic market position, which drives improved SCM performance through increased customer satisfaction. Results from Hult, Ketchen, and Arrfelt (2007) study "indicate that a firm that devotes a great deal of effort on developing a supply chain culture focused on satisfying the market (i.e., culture of competitiveness) is likely to reap positive advantages in stable market environments" (p. 1047). However, results from this same study also suggest the development of a culture of competitiveness within an organization supply chain must be complemented by knowledge development in order to further mitigate the risk of negative environmental influences on their operations (Hult, Ketchen, \& Chabowski, 2007). This implies a dependency between external environment factors (e.g., culture of competitiveness) and process orientation (e.g., knowledge development). Chen and Paulraj (2004a) also highlighted competitive priorities as a key input to the development of a strategic supplier base, which they argue will result in improved buyer/supplier performance. 


\subsection{External vs. Internal Integration}

Much of the research focuses on external integration - i.e. integration between and organization and its partners, such as customers, suppliers, governmental agencies, etc. However, discussion within the research quickly pivots to the importance of an organization's internal supply chain integration as well as the need for integration between people, process, and technology. For example, in their discussion of supply chain strategy typologies and its impact on firm performance, Narasimhan et al. (2008) define supply chain integration as linking "a firm with its customers, suppliers, and other channel members by integrating their activities, functions, processes, and locations...this includes strategic alliances, collaborative integration, and close and interactive long-term relationships with a firm's external suppliers" (p. 8, 12). This is evident as some large retailers have dedicated supply chain resources from their supplier base who are co-located and embedded within their organization, "such as a Proctor \& Gamble representative located at Wal-Mart's headquarters" (Crook et al., 2008) whereby, the activities of these resources include: forecasting, order management and replenishment, and special projects/strategic initiatives.

According to Fabbe-Costes. and Jahre (2008) external integration, such as that with customers and suppliers, has a significant impact on internal integration, which, in turn, leads to improved supply chain outcomes. Therefore, external integration itself does not lead to successful supply chain outcomes. For example, a supplier may seek to develop an integrated supply chain with one of its major customers to leverage the customer's sales data to improve the product replenishment process from an order-to-cash perspective. This customer-driven data is often leveraged by suppliers to internally increase operational efficiencies and improve on-time-in-full deliveries to its customers, resulting in a win-win scenario. As a result, the supplier must ensure there is internal integration (i.e. between IT, sales, and supply chain) to ensure the appropriate infrastructure is developed to support the use of the customer data for its intended purpose. This external integration is also highly dependent upon the organization's internal processes and systems capabilities. For example, when organizations adopt an Enterprise Resource Planning (ERP) solution to manage, in part, its supply chain activities (e.g. order management), the ERP system must be well-integrated -primarily from a process and technology perspective- with other internal supply chain systems and processes across the chain. For example, organizations may have also adopted technology applications in their manufacturing plants and distribution centers, whereby these systems are co-dependent with the ERP system relative to data transfer. Furthermore, these systems and processes must be well-coordinated with our trading partners, such as suppliers and customers, who may also benefit from the exchange of pertinent data.

Although these examples appear to be primarily "technology-focused," there is also an important "process" component here as well. These data-driven capabilities are designed to enable (and integrate) an organization's existing supply chain processes, which should be documented in form of process/value stream maps, user and training manuals, and Standard Operating Procedures (SOP's). Supported by the appropriate people resources, "process integration mediates the link between IT infrastructure and firm performance" (Vickery et al., 2010). This further supports the need for strong coordination between the various functions within the supply chain and the underlying business processes and organizational structure within those functions. That level of coordination must also carry over to the organization's various trading partners and other "connected" entities, which will result in supply chain integration.

\subsection{The Fifth Factor Summarized}

There is a strong parallel between supply chain integration and integration from a broader business perspective. According to Wharton@Work (2015) "no function is an island. A business is an integrated unit. You can't have operations without the customer, or marketing without finance” (para. 2). And, this is the same for the supply chain. Supply chains must operate in an integrated fashion, whereby supply chain leaders must possess the ability to think with an "integrated" and "end-to-end" mindset. "Few business leaders have what (is called) an 'enterprise mindset,' one that recognizes the integration 
and interdependency of every function” (Wharton@Work, 2015). This concept of supply chain integration, in both research and practice, has been widely supported and discussed from an empirical perspective in more recent years; and, it is believed that the more integration the better (Deshpande, 2012; Fabbe-Costes. \& Jahre, 2008). Despite this, there are limitations to much of the existing research in terms of how people, process, information technology, and consideration of external environment factors must be well-integrated and understood by supply chain managers to positively impact SCM performance. According to Deshpande (2012) all aspects of the supply chain should be fully understood and embraced to achieve a successful implementation of the supply chain. But, how is this put into practice?

\section{Implications for Supply Chain Managers}

Findings from this study provide significant contributions to the management practitioner community; and, therefore, strong implications regarding how supply chain managers must leverage existing capabilities or help organizations build the capabilities needed to drive greater supply chain integration. This can be achieved through the development of well-defined process improvement plans; investigation into new and emerging technologies; and, development of human capital required to operationalize and support supply chain integration.

\subsection{Develop Process Improvement Approach}

Supply chain managers must carefully dissect end-to-end supply chain processes as a first step in achieving supply chain integration given the enormous complexity associated with inter-organizational coordination of supply chain activities. For example, Burnette (2018) warns that the process of achieving (external) supply chain integration is far from simple and must include the process mapping of each point of integration within the chain to determine where in the supply chain processes are not currently integrated. This requires the use of tools and techniques found within the Lean/Six Sigma toolbox, such as Value Stream Mapping. "Value stream mapping is a paper and pencil tool that helps you to see and understand the flow of material and information as a product or service makes its way through the value stream". Burnette (2018) provides an example where a Tier 1 supplier produces a component for a manufacturer, yet both parties have very different supply chain strategies; whereby, the Tier 1 supplier is operating on a "throughput" strategy and the manufacturer is operating on a "responsiveness" strategy. In this example, the manufacturer must analyze this "link" in the relationship to determine if there is any value to integrating this part of the supply chain.

Internal supply chain integration, or integration among two or more supply chain functions (e.g. Source, Make), is also far from simple in that individual supply chain functions will often have performance objectives that may have a negative impact on the performance of another function. This leads to competing priorities and sub-optimization across the supply chain. According to Wharton@Work(2015) "it's not about optimizing your area or product, but rather improving the performance of the whole system" (para. 2). For example, an organization may engage the lowest-cost supplier to provide a major raw material at the expense of poor quality and customer service. The organization may initially benefit from lower cost-of-goods-sold, yet the same organization may incur costs further downstream in the supply chain due to product disposal, delayed production, late deliveries and/or product returns.

\subsection{Investigate Emerging Technologies}

From an internal integration perspective, the emergence of artificial intelligence (AI) in SCM is serving as a tremendous benefit to enhancing supply chain integration and overall supply chain improvement. Machine Learning, an AI approach, is used to collect large volumes of current and historical information and leveraging that information to make better decisions for the future. For example, Machine Learning can be used to improve forecast accuracy by carefully analyzing correlations and patterns in demand through predictive analytics (Columbus, 2019). Furthermore, Machine 
Learning can be used to power Blockchain technology, which acts as a digital ledger for information safe-keeping. In fact, more and more tools are being developed in this space to reduce forecast error, optimize inventory levels, and improve overall supply chain performance. Integration plays a significant role in that the forecast data obtained from the AI tool can be provided, through automation, to other internal supply chain partners, such as those resources managing inventory levels for the various storage locations further downstream in the supply chain. In addition, some level of integration is required much earlier in the process to feed the predictive analytics tool. Such formation may be supplied by external partners, such as suppliers and customers and/or internal partners, such as sales and marketing.

Machine learning can also be applied in the management of a manufacturer's supplier base. "Using machine learning and advanced analytics manufacturers can discover quickly who their best and worst suppliers are, and which production centers are most accurate in catching errors" (Columbus, 2019). In this case, integration occurs in an automated fashion, whereby performance data is captured and leveraged to make better decisions about the supplier evaluation and selection process. Moreover, a feedback loop can be established to report the details of supplier and production performance back to their respective partners/functions.

\subsection{Invest in Human Capital}

Finally, there are implications regarding the human capital required to improve end-to-end supply chain performance outcomes through supply chain integration. And, that human capital translates not only to current supply chain professionals requiring continuous development to further promote a culture of supply chain integration, but to college students who study SCM in their respective colleges and universities; and, who are part of the pipeline needed to backfill current SCM professionals. Therefore, SCM education within organizations and higher education is explored.

Although Burnette (2018) focuses on the "mechanics" associated with identifying integration points within and between organizations, Burnette (2018) also stresses the importance of soliciting the best supply chain talent to execute supply chain integration. Specifically, Burnette (2018) strongly encourages the investment in the recruitment and development of that talent to possess the ability to integrate the supply chain with an end-to-end focus. Therefore, underlying the concept of supply chain integration is the need for supply chain managers to possess the skills and abilities required to bring supply chain integration to life. Moreover, this research provides strong implications regarding how supply chain managers are recruited, on-boarded, trained, and developed throughout their career. For example, organizations must recruit and hire supply chain managers who are able to "think outside of the box" by tailoring their approaches with different stakeholders throughout the organization to solve SCM issues and drive better SCM performance (Fawcett et al., 2008). The on-boarding process should require that new supply chain managers to quickly connect, via one-on-one discussions, with counterparts from other functions in an effort to understand the relevance of those functions to the supply chain manager's role and responsibility in addition to the goals, objectives, and potential tradeoffs associated with the function. Ongoing professional development should include required courses that promote end-to-end supply chain integration of internal and external partners. For example, CorpU, in conjunction with Penn State University's Smeal College of Business, offers supply chain professional development courses as part of its Supply Chain Leadership Academy. One of these courses is "Achieving End-to-End Supply Chain Excellence," which is designed to help supply chain managers:

- "Understand core principles and implications of end-to-end supply chain management.

- Investigate how the core principles and interdependencies of end-to-end supply chain management impact procurement, demand planning, manufacturing, and logistics.

- Apply the core principles to your own organizational business challenges. 
- Enhance knowledge of the organization's end-to-end supply chain with the aim of creating value and capitalizing on synergies within the firm".

There are also academic implications associated with the importance of supply chain integration. Supply chain courses and programs in higher education have increased in recent years due, in part, to the high demand for talented supply chain professionals who possess supply chain knowledge, skills, and abilities through formal supply chain education and hands-on experience. However, there is an existing gap within many current supply chain curriculums as they do not include courses that focus primarily on developing a culture of supply chain integration, which is lacking among supply chain professionals across organizations today. Therefore, supply chain curriculums should include courses similar to the supply chain leadership courses offered. This may include courses in "Systems Theory," "Achieving End-to-End Supply Chain Excellence," or any customized course designed to promote a "supply chain integration" mindset.

\subsection{Further Engage in Knowledge-Sharing and Collaboration}

Knowledge-sharing through collaboration with trade partners and internal functions is another important managerial implication from this study as it gives importance to the relationships developed through supply chain integration. This study also identified the impact of trade partner collaboration on the effectiveness of supply chains. According to scholars, the development and maintenance of longterm supply chain relationships, including strategic supply chain partnerships with suppliers and customer, is vital to SCM success (Chen et al., 2004; Crook et al., 2008; Deshpande, 2012; Zacharia et al., 2009). This finding is important because it demonstrates the ability of organizations to effectively leverage its people to work with others in and outside of the organization to collaborate on supply chain activities and ultimately impact performance. At the core of this collaboration is the willingness of partners to share information that could benefit both parties from a supply chain perspective. Customers will often engage in top-to-top executive-level meetings throughout the year with their most strategic suppliers. The purpose of these meetings is to align on strategic supply chain priorities throughout the year by sharing details on major plans and initiatives not available to the public. For example, a customer may be planning to launch a major improvement to its existing ecommerce capabilities, which may have a major impact on how the manufacturer packages and delivers product to the customer in support of the ecommerce channel. Furthermore, this may result in future integrated project teams designed to operationally execute the newly-defined ecommerce strategy. Overall, a culture of integration requires a culture of knowledge-sharing, which should be accomplished through a formalized supply chain collaboration approach.

\section{Conclusion}

The initial goal of this systematic review was to identify organizational factors influencing supply chain performance outcomes, whereby four broad factors were uncovered: people, process, technology, and external environment. However, what emerged from the research was a very important fifth factor: Supply chain integration. Supply chain integration promotes an end-to-end cross-functional view of the supply chain to better understand tradeoffs (i.e. use low cost carriers could result in poor service through missed or late deliveries) and capitalize on functional dependencies and economies of scale. Figure 6 illustrates the conceptual framework that incorporates insights obtained through this research. In this model, supply chain integration can be viewed in a few different ways. The three circles at the top of the diagram represent the "external" integration that must be considered relative to how the organization coordinates with its trading partners and government agencies (e.g. Food and Drug Administration, or FDA). While the remaining circles represent the internal supply chain functions within the organization and the importance of these functions working together, from an end-to-end perspective to achieve the most successful outcome for the organization vs. the individual function. Furthermore, the inner circle portrays the importance of coordination between the organizations' internal resources: people, processes, and technology. Based on this impact, the organization's 
resources may need to react in an integrated fashion, potentially through process or technology changes, to attain positive performance outcomes.

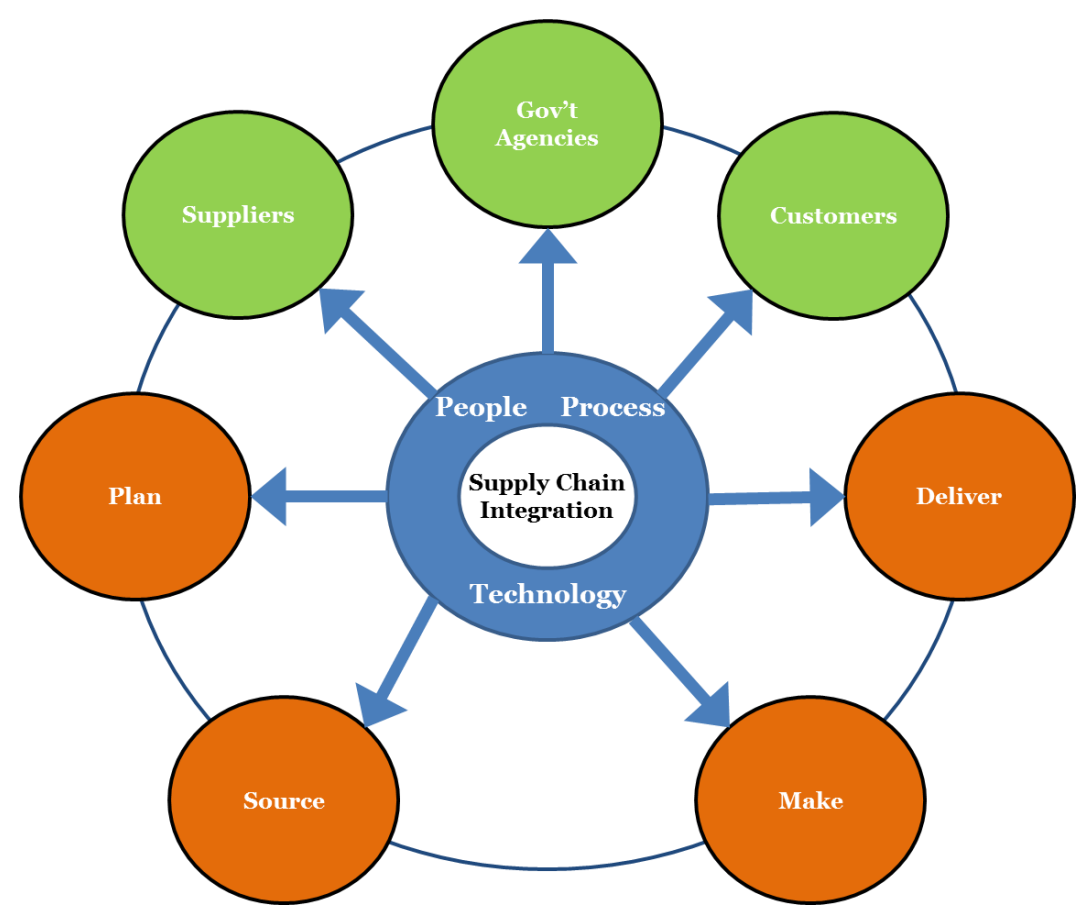

Figure-6. Conceptual framework: Supply chain integration.

The contributions of this research provide several important contributions to the field of management despite its limitations. First, the number of studies in the dataset used to conduct the EBRS is limited, partly due to the modernity of SCM and its existence as a key domain within the field of management. Although the 21 studies were drawn from various types of organizations and industries, a much larger dataset could have used to study the factors influencing SCM outcomes as well as the importance of supply chain integration. In fact, a larger dataset would likely yield additional factors impacting SCM performance and provide additional insight into the impact of the integration of these factors on SCM performance. Although the evidence from the literature review identifies several factors which must cohesively work together to improve SCM performance, there is a clearer path in terms of how these factors should be integrated.

Finally, the integrative nature of people, process, technology, and external environmental factors within SCM has a significant impact on the success of supply chain managers to positively impact SCM performance. Therefore, future researchers should continue to explore the role of supply chain integration in enhancing SCM performance. With additional research in this area, organizations can obtain more conclusive evidence to link SCM performance to supply chain integration.

\section{References}

APICS-The Association for Operations Management. (2008). APICS operations management body of knowledge framework (2nd ed.). Chicago, IL: APICS.

Beamon, B. M. (1999). Measuring supply chain performance. International Journal of Operations \& Production Management, 19(3), 275-292.

Brammer, S., Hoejmose, S., \& Millington, A. (2011). Network for business sustainability. Managing sustainable global supply chains: A systematic review of the body of knowledge.

Brewer, P. C., \& Speh, T. W. (2000). Using the balanced scorecard to measure supply chain performance. Journal of Business Logistics, 21(1), 75-75. 
Briner, R. B., Denyer, D., \& Rousseau, D. M. (2009). Evidence-based management: concept cleanup time? Academy of Management Perspectives, 23(4), 19-32.Available at: https://doi.org/10.5465/amp.2009.45590138.

Burnette, M. (2018). What is end-to-end supply chain integration video file. Retrieved from: https://www.supplychainbrain.com/media/videos/play/4922-what-is-end-to-end-supply-chain-integration.

Chen, I. J., \& Paulraj, A. (2004a). Towards a theory of supply chain management: The constructs and measurements. Journal of Operations Management, 22(2), 119-150.Available at: https://doi.org/10.1016/j.jom.2003.12.007.

Chen, I. J., \& Paulraj, A. (2004b). Understanding supply chain management: Critical research and a theoretical framework. International Journal of Production Research, 42(1), 131 -163.Available at: 10.1080/00207540310001602865.

Chen, I. J., Paulraj, A., \& Lado, A. A. (2004). Strategic purchasing, supply management and firm performance. Journal of Operations Management, 22(5), 505-523.Available at: 10.1016/j.jom.2004.06.002.

Columbus, L. (2019). How to improve supply chains with machine learning. Forbes. Retrieved from: https:// www.forbes.com/sites/louiscolumbus/2019/04/28/how-to-improve-supply-chains-with-machine-learning10-proven-ways/\#1740306e3f3c.

Crook, T. R., Giunipero, L., Reus, T. H., Handfield, R., \& Williams, S. K. (2008). Antecedents and outcomes of supply chain effectiveness: An exploratory investigation. Journal of Managerial Issues, 2O(2), 161-177.

Deshpande, A. (2012). Supply chain management dimensions, supply chain performance and organizational performance: An integrated framework. International Journal of Business and Management, 7(8), 2-19.

Fabbe-Costes, N., \& Jahre, M. (2008). Supply chain integration and performance: A review of the evidence. Management, 19(2), $130-154$.

Fabbe-Costes., N., \& Jahre, M. (2008). Supply chain integration and performance: A review of the evidence. International Journal of Logistics Management, 19(2), 130-154.Available at: 10.1 108/09574090810895933.

Fawcett, S. E., Magnan, G. M., \& McCarter, M. W. (2008). Benefits, barriers, and bridges to effective supply chain management. Supply Chain Management, 13(1), 35-48.Available at: https://doi.org/10.1 108/13598540810850300.

Forrester, J. W. (1958). Industrial dynamics. A major breakthrough for decision makers. Harvard Business Review, 36(4), 37-66.

Gough, D. (2007). Weight of evidence: A framework for the appraisal of the quality and relevance of evidence. Research Papers in Education, 22(2), 213-228.Available at: https://doi.org/10.1080/02671520701296189.

Hellström, D., \& Nilsson, F. (2011). Logistics-driven packaging innovation: A case study at IKEA. International Journal of Retail E Distribution Management, 39(9), 638-657.Available at: 10.1108/0959055111115932.

Hendricks, K. B., \& Singhal, V. R. (2005). Association between supply chain glitches and operating performance. Management Science, 51(5), 695-711.Available at: https://doi.org/10.1287/mnsc.1040.0353.

Hult, G. T. M., Ketchen, D. J., \& Arrfelt, M. (2007). Strategic supply chain management: Improving performance through a culture of competitiveness and knowledge development. Strategic Management Journal, 28(10), 1035-1052.Available at: https://doi.org/10.1002/smj.627.

Hult, G. T. M., Ketchen, J. D. J., \& Chabowski, B. R. (2007). Leadership, the buying center, and supply chain performance: A study of linked users, buyers, and suppliers. Industrial Marketing Management, 36(3), 393-403.Available at: https://doi.org/10.1016/j.indmarman.2005.12.002.

Kamaladevi, B. (2010). RFID - the best technology in supply chain management. International Journal of Innovation, Management, and Technology, 1(2), 198-204.

Kearney, A. T. (2017). Council of supply chain management professionals (CSCMP), and penske logistics. 29th Annual State of Logistics Report. Retrieved from: https://www.penskelogistics.com/insights/industry-reports/state-of-logisticsreport/.

Krabbe, M. (2007). Leverage supply chain innovation: Distribution center innovation puts you ahead of the competition. Industrial Engineer, 39(12), 26-31.

Li, Y. (2007). A research model for collaborative knowledge management practice, supply chain integration and performance. Doctoral Dissertation, University of Toledo.

Li, S., Ragu-Nathan, B., Ragu-Nathan, T., \& Rao, S. S. (2006). The impact of supply chain management practices on competitive advantage and organizational performance. Omega, 34(2), 107-124.Available at: https://doi.org/10.1016/j.omega.2004.08.002.

Mentzer, J. T., DeWitt, W., Keebler, J. S., Min, S., Nix, N. W., Smith, C. D., \& Zacharia, Z. G. (2001). Defining supply chain management. Journal of Business logistics, 22(2), 1-25.

Narasimhan, R., Kim, S. W., \& Tan, K. C. (2008). An empirical investigation of supply chain strategy typologies and relationships to performance. International Journal of Production Research, 46(18), 5231-5259.Available at: https://doi.org/10.1080/00207540600847137.

Petticrew, M., \& Roberts, H. (2006). Systematic reviews in the social sciences: A practical guide. Malden, MA: Blackwell Publishing.

Ramdas, K., \& Spekman, R. E. (2000). Chain or shackles: Understanding what drives supply-chain performance. Interfaces, 30(4), 3-21.Available at: https://doi.org/10.1287/inte.30.4.3.11644.

Reay, T., Berta, W., \& Kohn, M. K. (2009). What's the evidence on evidence-based management? Academy of Management Perspectives, 23(4), 5-18. 
Rousseau, D. M., Manning, J., \& Denyer, D. (2008). 11 evidence in management and organizational science: Assembling the field's full weight of scientific knowledge through syntheses. The Academy of Management Annals, 2(1), 475515.Available at: https://doi.org/10.5465/19416520802211651.

Rousseau, D. M., \& McCarthy, S. (2007). Educating managers from an evidence-based perspective. Academy of Management Learning Eं Education, 6(1), 84-101.Available at: https://doi.org/10.5465/amle.2007.24401705.

Stock, J. R., \& Boyer, S. L. (2009). Developing a consensus definition of supply chain management: A qualitative study. International Journal of Physical Distribution \& Logistics Management, 39(8), 690-711.

Su, S. I., Gammelgaard, B., \& Yang, S. (2011). Logistics innovation process revisited: Insights from a hospital case study. International Journal of Physical Distribution $\mathcal{E}^{\circ}$ Logistics Management, 41(6), 577-600.Available at: https://doi.org/10.1108/09600031111147826.

Tan, K. C., Kannan, V. R., Handfield, R. B., \& Ghosh, S. (1999). Supply chain management: An empirical study of its impact on performance. International Journal of Operations \& Production Management, 19(9/10), 1034-1052.

Thomas, J., \& Harden, A. (2008). Methods for the thematic synthesis of qualitative research in systematic reviews. BMC Medical Research Methodology, 8(1), 45.Available at: https://doi.org/10.1 186/1471-2288-8-45.

Vickery, S. K., Jayaram, J., Droge, C., \& Calantone, R. (2003). The effects of an integrative supply chain strategy on customer service and financial performance: An analysis of direct versus indirect relationships. Journal of Operations Management, 21(5), 523-539.Available at: https://doi.org/10.1016/j.jom.2003.02.002.

Vickery, S., Droge, C., Setia, P., \& Sambamurthy, V. (2010). Supply chain information technologies and organisational initiatives: Complementary versus independent effects on agility and firm performance. International Journal of Production Research, 48(23), 7025-7042.Available at: https://doi.org/10.1080/00207540903348353.

Webb, R. (2017). Shifting the operational mindset to process integration: How better business processes improve operational performance and disruption management. Retrieved from https://www.sabreairlinesolutions.com/images/uploads/ascend/Shifting_Mindset.pdf.

Wharton@Work. (2015). The enterprise mindset: Developing an integrated approach to your business. Retrieved from https://executiveeducation.wharton.upenn.edu/thought-leadership/wharton-at-work/2015/02/the-enterprisemindset/.

Zacharia, Z. G., Nix, N. W., \& Lusch, R. F. (2009). An analysis of supply chain collaborations and their effect on performance outcomes. Journal of Business logistics, 30(2), 101-123.Available at: https://doi.org/10.1002/j.21581592.2009.tboo 114.x. 